\title{
Differences in individual life path choices affecting life expectancy and health in Russia
}

\author{
Tatiana Berezina ${ }^{1, *}$ \\ ${ }^{1}$ Moscow State University of Psychology and Education, Moscow, Russia
}

\begin{abstract}
In this study we examined 100 pairs of monozygotic (MZ) twins to determine if lifestyle differences between control and experimental twins affected lifespan and health. We used the twin database of the Russian Humanitarian Scientific Foundation. The dependent variables were the difference in lifespan and the number of socially significant diseases between control and experimental twins. The independent variables were the differences within different psychosocial factors (education, family, children, career, prosocial behavior, religiousness, residence, relocations) between control and experimental twins. Using the ANOVA test, we obtained that career $(\mathrm{F}=11.12, \mathrm{p}=0.000)$, education $(\mathrm{F}=3.272, \mathrm{p}=0.042)$, living in a large city $(\mathrm{F}=6.674, \mathrm{p}=0.008)$, having family $(\mathrm{F}=3.926, \mathrm{p}=0.023)$ and relocations $(\mathrm{F}=3.757, \mathrm{p}=0.046)$ increased lifespan. For women, one of the most significant positive factors that increased lifespan was education $(\mathrm{F}=5.992, \mathrm{p}=0.005)$. For men, relocation $(\mathrm{F}=7.835, \mathrm{p}=0.027)$ was one of the most significant factors that increased lifespan. Having family significantly reduced the number of socially significant diseases $(F=3.477, p=0.035)$. Although this study represents statistically significant data showing that distinct lifestyles have different effects on lifespan and health, future studies with a database of a larger amount of $\mathrm{MZ}$ twin pairs are needed to confirm this data.
\end{abstract}

\section{Introduction}

Personal lifestyles depend on individual choices or psychosocial factors that include education, having family and/or children, choice of residence and career. It is well known that in different historical periods and in different countries, different psychosocial factors had an effect on lifespan. For example, in Europe, aristocrats possessed much longer lifespans than rural inhabitants. Human longevity has now been considered more dependent on environment and epigenetics than on genetic factors [1]. Based on the lifespan studies of twins born in Denmark in the late 19th century, it was found that longevity was only $25 \%$ dependent on genetic factors, and the rest (75\%) was dependent on environmental factors. The twin studies performed in Russia confirmed this data and showed that in Russia, in the 20 century, lifespan was $36 \%$ dependent on heredity and $64 \%$ dependent on environmental factors. The environmental factors included specificities of family lifestyle and family nurture as well as specificities of individual lifestyle choices in adulthood [2]. Lifespan is

\footnotetext{
*Corresponding author: tanberez@bk.ru
} 
also correlated with health, but the correlation was found only among centenarians (over 90100 years old), and it was dependent only on heredity Several genetic pathways have been found to increase lifespan. The longevity genes may slow down age-related changes in the cells, and increase resistance to environmental negative influences such as infections and injuries [3]. However, only a few genes involved in genetic susceptibility to longevity have been identified [4]. Using genealogical methods, the relationship between health and lifespan of Chinese [5] and Japanese [6] centenarians has been observed. Interestingly, Russian studies found that lifespan is more dependent on access to health care than on health itself. Career achievements have also shown beneficial effects on health [7]. Other psychosocial factors affecting lifespan include education [8], prosocial behavior [9], extreme lifestyle [10], optimism and positive emotions [11 -12], stress resistance [13], family socioeconomic status [14], having a family [15], and the number of children in a family [16]. However, the positive effects of different psychosocial factors on lifespan and health are still unclear. We are the first in Russia who have used the twin method to study the effect of psychosocial factors on lifespan and health. In this study we analyzed lifestyle specificities of monozygotic (MZ) twins who lived and died in Russia in the 20th century with consideration to various psychosocial factors (education, family, career, place of residence). We found that education, career growth, and social mobility (frequent in-country moving) significantly reduced the risk of premature death. Frequent relocations not only reduced the risk of premature death, but also increased overall lifespan and improved health among young men. Having children, as well as career growth and an education, increased the lifespan of older individuals. We have also, for the first time, showed the advantage of living in large cities in Russia. Living in large cities showed an increase of lifespan in older individuals, and a reduced risk of premature death. We have also found differences in psychosocial factors affecting lifespan and health between Russian men and women.

\section{Methods}

\subsection{Participants}

In the present study we used a database of twins from the Russian Humanitarian Scientific Foundation (Project \# 16-06-50020). We analyzed 100 pairs of MZ twins (44 pairs were female and 56 pairs were male). The earliest born pairs of twins were born in 1866, and the most recently born pair was in 1985. The main lifespan of twins occurred on the 2nd half of the 20th century. Average lifespan of the twins was 53.2 years (62.3 years for females, 48.8 years for males). This corresponds to the dynamics of life expectancy in Russia in the 20th century. The maximal age was 108 years, and the minimal age was 14 years old. A group of twins $(\sim 16 \%)$ had died because of violent causes (accident, murder or suicide). The average lifespan of this group was 28.8 years. The remaining $84 \%$ of twins had died because of natural causes. The average lifespan of this group was 67.05 years. Moreover, 52 pairs of twins, in which each twin lived more than 50 years, were placed in a separate group. The detailed distribution of MZ twins by place of residence and by date of birth and death is summarized in Table 1 and 2, respectively.

Table 1. MZ twin place of residence (in \%).

\begin{tabular}{|c|c|c|c|c|}
\hline $\begin{array}{c}\text { Capital (Moscow, } \\
\text { Russia) }\end{array}$ & Big city & City or town & County or village & N/A \\
\hline 22 & 22 & 18 & 10 & 28 \\
\hline
\end{tabular}

Table 2. Date of birth and death of MZ twins (in \%). 


\begin{tabular}{|c|c|c|c|c|c|}
\hline \multicolumn{3}{|c|}{ Date of birth } & \multicolumn{3}{c|}{ Date of death } \\
\hline $\begin{array}{c}\text { The end of IXX } \\
\text { century }\end{array}$ & $\begin{array}{c}\text { First half of } \\
\text { XX century }\end{array}$ & $\begin{array}{c}\text { Second half of } \\
\text { XX century }\end{array}$ & $\begin{array}{c}\text { First half of } \\
\text { XX century }\end{array}$ & $\begin{array}{c}\text { Second half of } \\
\text { XX century }\end{array}$ & $\begin{array}{c}\text { XXI } \\
\text { century }\end{array}$ \\
\hline 14 & 29 & 57 & 14 & 26 & 60 \\
\hline
\end{tabular}

\section{Methods of Gathering Data}

\subsection{Co-twin Control Method}

We investigated 100 pairs of MZ twins using the co-twin control method as previously described [17]. An experimental twin was a twin with the longer lifespan. A control twin was the twin with the shorter lifespan. We collected the following twin data:

1) Date of birth and death.

2) Gender.

3) Marital status.

4) Causes of death: natural (illness, old age) or violent (accident, murder, suicide).

5) Health data (socially significant diseases). In Russia, the socially significant diseases are often considered as diseases that cause death. We analyzed the following socially significant diseases: cardiovascular diseases, cancer, respiratory diseases and endocrine system diseases.

6) Data on residence and relocation.

7) Prosocial behavior.

8) Number of children.

9) Education.

10)Career.

11) Religiousness.

The differences between the experimental and control twins were analyzed using the following factors: 1) Lifespan (the difference in years between the lifespan of the experimental and control twins); 2) The number of diseases (the difference in the number of socially significant diseases between experimental and control twins); 3) Education: incomplete secondary, secondary, secondary special, higher, scientific degree (one point/each education). 4) Children. The difference in the number of children between experimental and control twins was recorded; 5) Career. The level of career achievements was estimated by the following scale: 1 point - low level; 2 points- medium level, 3 points high level; and 4 points - very high level; 6) Prosocial behavior (the number of individuals/relatives supported by each twin); 7) Religiousness. It was assessed on a 3-point scale: 0 points - religiosity was absent (atheist or agnostic); 1 point - religiosity was present, 2 points - pronounced religiosity (monasticism, religious order, etc.). 8) Place of residence. It was estimated using the following scale: 1 point -a village; 2 points - a town; 3 points - a large city (such as a regional center), 4 points - the capital (Moscow). In the case of a twin living in several places, the one where the twin spent most of his life was taken. 9) Number of relocations.

\subsection{Statistics}


We used the One-way Analysis of variance (ANOVA) test to examine the impact of the psychosocial factors (education, family, children, career, prosocial behavior, religiousness, residence, number of relocations) on lifespan and health between control and experimental twins. The dependent variables were the differences in lifespan and number of socially significant diseases between control and experimental twins. The independent variables were the differences in education, family, children, career, prosocial behavior, religiousness, residence, and the number of relocations between control and experimental twins. $P<0.05$ was considered statistically significant.

\section{Results}

\subsection{Effects of psychosocial factors on lifespan and health}

The psychosocial factors such as career, education, living in a large city, having family and relocations statistically significantly $(\mathrm{p}<0.05)$ increased lifespan. But the psychosocial factors such as children, religiousness, and prosocial behavior did not affect lifespan. The number of socially significant diseases was increased parallel to career growth. Having family statistically significantly $(\mathrm{p}<0.05)$ decreased the number of socially significant diseases. The number of socially significant diseases was not affected by education, number of children, prosocial behavior, religiosity, or place of residence and number of relocations (Table 3).

Table 3. Effects of MZ twin lifestyles on lifespan and number of socially significant diseases.

\begin{tabular}{|c|c|c|c|c|c|c|}
\hline \multirow{2}{*}{$\begin{array}{c}\text { Psychosocial } \\
\text { factors }\end{array}$} & \multicolumn{3}{|c|}{ Lifespan } & \multicolumn{3}{c|}{ Number of diseases } \\
\cline { 2 - 7 } & Effect & $\mathbf{F}$ & $\mathbf{p}$ & Effect & F & p \\
\hline Education & increased & 3.272 & $0.042^{*}$ & no & 0.491 & 0.614 \\
\hline Family & increased & 3.926 & $0.023^{*}$ & decreased & 3.477 & $0.035^{*}$ \\
\hline Children & no & 1.424 & 0.214 & no & 0.968 & 0.451 \\
\hline Career & increased & 11.12 & $0.000^{*}$ & increased & 10.30 & $0.000^{*}$ \\
\hline Prosocial behavior & no & 0.745 & 0.390 & no & 1.111 & 0.294 \\
\hline Religiosity & no & 0.093 & 0.911 & no & 1.675 & 0.193 \\
\hline Place of residence & incresed & 6.674 & $0.008^{*}$ & no & 0.111 & 0.895 \\
\hline $\begin{array}{c}\text { Number of } \\
\text { relocations }\end{array}$ & increased & 3.757 & $0.046^{*}$ & no & 0.754 & 0.486 \\
\hline
\end{tabular}

$* \mathrm{p} \leq 0.05$

\subsection{Sexual differences in lifespan and health}

The effects of different lifestyles on lifespan and number of socially significant diseases in MZ twin women and MZ twin men are presented in Table 4 and Table 5, respectively. In women, education, career growth, and living in a large city statistically significantly $(p<0.05)$ increased lifespan. Interestingly, having family (or marriage) statistically significantly $(\mathrm{p}<0.05)$ decreased lifespan in women. Religiousness, children and prosocial behavior did not affect lifespan in women. Career growth increased the number of socially significant diseases in women (Table 4). 
Table 4. Effects of lifestyles of female MZ twins on lifespan and number of socially significant diseases.

\begin{tabular}{|c|c|c|c|c|c|c|}
\hline \multirow{2}{*}{ Psychosocial factors } & \multicolumn{3}{|c|}{ Lifespan } & \multicolumn{3}{c|}{ Number of diseases } \\
\cline { 2 - 7 } & Effect & F & p & Effect & F & p \\
\hline Education & increased & 5.992 & $0.005^{*}$ & no & 0.853 & 0.434 \\
\hline Family & decreased & 3.829 & $0.030^{*}$ & no & 1.954 & 0.155 \\
\hline Children & no & 0.579 & 0.680 & no & 1.743 & 0.161 \\
\hline Career & increased & 16.24 & $0.000^{*}$ & increased & 5.105 & $0.029^{*}$ \\
\hline Prosocial behavior & no & 0.973 & 0.330 & no & 2.342 & 0.134 \\
\hline Religiosity & no & 0.278 & 0.601 & no & 1.734 & 0.195 \\
\hline $\begin{array}{c}\text { Place of residence } \\
\text { increased }\end{array}$ & 8.347 & $0.003^{*}$ & no & 1.020 & 0.382 \\
\hline $\begin{array}{c}\text { Number of } \\
\text { relocations }\end{array}$ & no & 2.379 & 0.123 & no & 1.236 & 0.315 \\
\hline
\end{tabular}

$* \mathrm{p} \leq 0.05$

Table 5. Effects of lifestyles of male MZ twins on lifespan and number of socially significant diseases.

\begin{tabular}{|c|c|c|c|c|c|c|}
\hline \multirow{2}{*}{ Psychosocial factors } & \multicolumn{3}{|c|}{ Lifespan } & \multicolumn{3}{c|}{ Number of diseases } \\
\cline { 2 - 7 } & Effect & $\mathbf{F}$ & $\mathrm{p}$ & Effect & F & $\mathrm{p}$ \\
\hline Education & no & 0.629 & 0.431 & no & 0.323 & 0.572 \\
\hline Family & no & 0.951 & 0.393 & no & 0.856 & 0.431 \\
\hline Children & increased & 3.242 & $0.013^{*}$ & increased & 4.260 & $0.003^{*}$ \\
\hline Career & increased & 10.12 & $0.000^{*}$ & increased & 10.12 & $0.000^{*}$ \\
\hline Prosocial behavior & no & 0.213 & 0.646 & no & 0.598 & 0.443 \\
\hline Religiosity & no & 0.003 & 0.959 & no & 3.081 & 0.085 \\
\hline Place of residence & increased & $\mathbf{9 . 9 4 2}$ & $\mathbf{0 . 0 1 6 *}$ & no & 0.003 & 0.959 \\
\hline $\begin{array}{c}\text { Number of } \\
\text { relocations }\end{array}$ & increased & $\mathbf{7 . 8 3 5}$ & $\mathbf{0 . 0 2 7 *}$ & decreased & 4.645 & $0.003 *$ \\
\hline
\end{tabular}

$* \mathrm{p} \leq 0.05$

Men's lifespans were increased by career growth, relocations, and living in big cities. In contrast to women, men who had children had an increased lifespan. The educational level of men did not have an effect on their lifespan. The presence of family, prosocial behavior, and religiousness did not have an effect on the men's lifespans. In contrast to women, the number of socially significant diseases in men is affected by a large number of psychosocial factors. The most important factor was the number of relocations. For men, relocations 
reduced the number of diseases and, therefore, improved health. The improvement of health was related to increased lifespan. Men who had children had a greater number of diseases and, therefore, worse health. However this factor did not reduce lifespan in men, but vice versa, it increased it as we described above. We speculate that men who had children had more positive emotions than men without children, which led to increased lifespan even when there was some diminishment in health. Career growth in men was also associated with an increased number of socially significant diseases. Education, family, religiosity, prosocial behavior, and place of residence did not have an effect on the number of socially significant diseases in men.

\subsection{Psychosocial factors affecting lifespan and health in older MZ twins}

The effects of different lifestyles on lifespan and health in older twins (in couples where both twins lived more than 50 years) are presented in Table 6 . The impact of religiosity was not taken into account, because among the older twins, there was not a single pair who showed any differences in religiosity. Lifespan in older age was increased by education, having children, career growth, and living in large cities. Family and prosocial behavior did not have an effect on lifespan of older twins. The importance of the factor "the number of relocations" decreased for older twins. The health factor is also influenced by one's career, and the number of children. Career growth and having children increased the number of diseases in older twins, but at the same time, these factors also increased the lifespan of older twins.

Table 6. Effects of lifestyles of older MZ twins (in pairs where both twins lived more than 50 years) on lifespan and number of socially significant diseases.

\begin{tabular}{|c|c|c|c|c|c|c|}
\hline \multirow{2}{*}{ Psychosocial factors } & \multicolumn{4}{|c|}{ Lifespan } & \multicolumn{3}{c|}{ Number of diseases } \\
\cline { 2 - 7 } & Effect & $\mathbf{F}$ & $\mathbf{p}$ & Effect & F & p \\
\hline Education & increased & 9.989 & $0.000^{*}$ & no & 0.200 & 0.819 \\
\hline Family & no & 0.185 & 0.832 & no & 2.332 & 0.108 \\
\hline Children & increased & 3.618 & $0.008^{*}$ & increased & 2.631 & $0.036^{*}$ \\
\hline Career & increased & 9.176 & $0.000^{*}$ & increased & 4.924 & $0.011^{*}$ \\
\hline Prosocial behavior & no & 0.194 & 0.662 & no & 2.598 & 0.113 \\
\hline Religiosity & N/A & N/A & N/A & N/A & N/A & N/A \\
\hline $\begin{array}{c}\text { Place of residence } \\
\text { increased }\end{array}$ & $\mathbf{4 . 0 8 9}$ & $\mathbf{0 . 0 4 2 *}$ & no & 1.625 & 0.234 \\
\hline $\begin{array}{c}\text { Number of } \\
\text { relocations }\end{array}$ & no & $\mathbf{1 . 6 1 9}$ & $\mathbf{0 . 2 3 6}$ & no & 3.250 & 0.072 \\
\hline
\end{tabular}

$* \mathrm{p} \leq 0.05$

\section{Discussion}


In the current studies we used the following principles for the interpretation of our data: i) If a psychosocial factor had effects on the entire studied group, but did not affect individuals older than 50 years, we interpreted it as a factor that reduces risk of premature death, but it does not increase lifespan. ii) If a factor had effects on lifespan of people older than 50 years, we interpreted it as a factor that increases lifespan and that it is especially important for increasing lifespan of older adults. iii) If a factor reduced the number of socially significant diseases and increased (or did not affect) lifespan, we considered it a factor that improves health outcomes and life quality but which does not increase lifespan. iv)If a factor increased both the number of diseases and lifespan, we believe that the increase in the number of diseases is a consequence of a longer life and is not associated with health. It is also important to take into account that all the psychosocial factors affecting lifespan and health were obtained from Russia in the 20th century. In other countries and in other time periods, they may differ. The 20th century was a difficult period in the history of Russia. This period is characterized by a large number of social cataclysms. At the beginning of the century there was World War I, the Russian Revolution, and Civil War followed by the creation of the Soviet Union. In the middle of the century there was World War II, and at the end of the century there was the restructuring, disintegration and collapse of the Soviet Union and the creation of the Russian Federation. All these historical periods were accompanied by changes in personal lifestyles. However, despite the social upheavals, there were also changes that were, to varying degrees, positive for people. These were industrialization, a decrease in rural population and an increase of urban population, migration of a large number of people within the country, scientific and technical progress, free medical care, free universal compulsory education for children, free education in college, and the coming to power of the broad masses of the people. All of this led to an increase of life expectancy during the 20th century. Thus at the beginning of the century, the life expectancy at birth was 42.93 years (for 1926-1927), and by the end of the century it increased to 69.19 years (for 1990), and reached 71.9 years for 2016 (data of Russian Federation Federal State Statistics Service: http://www.gks.ru/). According to our study, relocations, moving to big cities, high education levels, and career growth increased lifespan. In other words, people who built their lifestyles in accordance with the social processes that are prominent in the country were favorable. This was a person who left the village for the city, got an education, and made a successful career. In different countries, many of these factors are traditionally considered to increase lifespan. For example, education is a positive factor for many countries and social groups. In the United States and in other low-mortality countries, highly educated individuals live longer on average than their low-educated counterparts [18]. The effects of other social factors such as number of relocations and place of residence were not so evident. In Russia in the 20th century, longevity was associated with a more traditional way of life, living in rural areas and the absence of relocations. According to statistical data obtained in the Soviet Union, the regions with the largest number of centenarians were the Caucasus and Yakutia, where rural areas with low levels of educated people were prevalent. The individuals with greater longevity from these areas had a traditional and simple life. They received less education, have never moved from their rural places and worked as shepherds in the mountains. According to the studies of Russian researchers, relocations may cause stress, which leads to a change of lifespan [19]. Researchers from other countries also confirmed that a lifespan of older adults was related to their lifestyles. They should live in a comfortable and familiar environment; have a network of positive social contacts and an active work with sufficient earnings. However, these conclusions were derived from the analysis of lifestyles of centenarians. Our present studies, using the twin method, have shown that moving to another city, getting better education, and career growth increased lifespan among all studied age groups and among both men and women. We found that religiosity did not affect longevity of people who lived in Russia in the 20th century. Evidently, this was due to the fact that 
religious believers were being widely targeted and persecuted for their belief or promotion of religion, so most people in Russia in the 20th century did not associate their lives with religion. In contrast, studies that took place in the U.S. and Europe showed that religiosity was associated with longer life and better physical and mental health for older adults [20]. Thus, in the U.S., lifespan is positively related to frequency of socializing with neighbors, religious participation, and volunteering [21]. On the other hand, in Russia in the 20th century, older adults were not associated with religion but practiced other forms of socializing such as communicating with neighbors, former colleagues, and relatives. It is well known that the objective existence of family relationships may increase lifespan [14]. We found that the presence of family was a positive psychosocial factor for all the studied groups. However for female twins, marriage and having children had negative effects. We speculate that the positive effects of marriage and having children on male twins are related to the fact that married men have more healthy behavior and more secure lifestyles than unmarried men. According our data, married women had lower lifespans than unmarried women. However, studies conducted in other countries showed that both unmarried men and women had higher mortality compared to married men and women [15]. The negative effect of having family for Russian women who lived in the 20th century is possibly explained by the 20th century "family or career" dilemma. Choosing a career for women reduced the chances of a happy family life, and vice versa, the choice of family reduced the possibility of successful career growth. For men, there was no such dilemma because men could simultaneously have a happy family life and a successful career. Our study has shown that having children extended lifespan of older men and women. This seems to be related to Russian traditions. Elderly parents usually live together with their children who support their parents morally and financially. Our study is correlated to a recent study of Swedish researchers who found a negative correlation between having children and mortality among older men and women. They concluded that older childless adults face support deficits, and that parents have more healthy behaviors than non-parents [22]. Many researchers believe that the correlation between health and lifespan exists only among older adults. In Russia in the 20th century, lifespan of even absolutely healthy individuals such as cosmonauts did not differ from average lifespan in the country [7]. We found a positive correlation between lifespan and number of diseases. Psychosocial factors such as career that increase lifespan also may indirectly increase the number of diseases. We believe that career itself does not affect negatively on health. We also found that having a family and number of relocations are negatively correlated with number of diseases. Our data demonstrated that having family lessened the number of diseases and increased lifespan. However, this was not confirmed for adults older than 50 years. Individuals who had a family in Russia in the 20th century had a reduced probability of a serious illness at a young age and a reduced risk of premature death. This is probably related to the fact that individuals who have a family are more restrained, take care of their health, and take fewer risks. They exhibit healthier behavior but only up to a certain age. To increase life expectancy in older age (older than 50 years), a person has to look for other psychosocial benefits, not just having a family. We found that an increase in the number of relocations led to a reduction in the number of diseases in men. Relocations not only increased absolute lifespan, but also reduced the risk of premature death from violent causes. Almost all of the relocations we found were from smaller towns to larger ones, where there were better medicine, salaries, socio-cultural environments, and living conditions. But relocations are also positive themselves, especially for young men, because we found that relocations reduced the number of socially significant diseases present. But we cannot exclude that this data reveals the fact that only healthy young men could easily change their place of residence and that relocations themselves have no effects on the number of diseases. We believe that positive psychosocial factors that increase lifespan and improve health may 
be perceived as beneficial personal resources that should be used at a young age. These resources include better education, successful career and having children.

In this study we obtained two groups of positive psychosocial factors: 1) those that increased absolute lifespan at an older age (after 50 years old), and 2) those that mitigated the risk of premature death (including violent death) at an age younger than 50 years old. The factors that increased absolute lifespan were higher educational levels, career growth, moving to a larger city and having children. We combined the first three factors because, on the one hand, these factors are associated with a general increase in the socioeconomic status of an individual and the increase in his/her ability to take care of his/her health. On the other hand, these factors indicate a high level of development of intellectual and goal-oriented personality traits that allow a person to get an education and make a career. Having children was a positive psychosocial factor in Russia. The positive effect of this factor is related to the fact that in Russia, grown-up children provide care for their elderly parents. The risk of premature death was basically reduced by the same factors that increased absolute lifespan: the level of education, career growth, and moving to a larger city. The presence of children did not reduce the risk of premature death, perhaps because most of the participants of the young group did not have children yet. But, the presence of family significantly reduced the risk of premature death, including violent death. Perhaps the presence of family made people more cautious, calmer, and less prone to risking their lives. A large number of relocations also reduced the risk of premature death. Perhaps relocations allowed young men to better solve their personal problems and avoid various threats. We also found that the presence of family reduced the number of diseases at a young age and improved health.

Our data indicated that career growth and moving to a larger city were the most positive psychosocial factors that increased lifespan among both men and women. Men also benefit from having children and from relocations. In general, high mobility is a very promising psychosocial factor for men. This factor not only increased lifespan but also reduced the number of socially significant diseases and improved health. But, education did not have an effect on the lifespan of men. Probably, in Russia, in the 20th century, there were opportunities for men to pursue a career and achieve social growth without high education. Instead, they could rely on social mobility and on their own desire and perseverance. In contrast, for women, the increase of the educational level increased lifespan, and, likely, promoted a career growth. But the focus on family is a negative psychosocial factor for women.

\section{Acknowledgments}

We wish to thank Dr. Irina Balan (University of North Carolina, Chapel Hill, NC, USA) and Ms. Anna Balan (Texas State University, San Marcos, TX, USA) for their help in translation of our manuscript from Russian to English and data interpretation and discussion.

This work was supported by Russian Foundation for Basic Research (RFBR) 18-01300092A.

\section{References}

1. D. Govindaraju, G. Atzmon and N. Barzilai, Appl Transl Genom 4, 23-32 (2015) https://doi.org/10.1016/j.atg.2015.01.001

$\begin{array}{llll}\text { 2. T. Berezina, Voprosy Psikhologii 2017(2), } & \text { 79-88 }\end{array}$

http://www.scopus.com/inward/record.url?eid=2-s2.0-

85026631075\&partnerID=MN8TOARS 
3. G. Passarino, F. De Rango and A. Montesanto, Immun Ageing 13, 12 (2016) doi: https://doi.org/10.1186/s12979-016-0066-Z

4. S. Dato, G. Rose, P. Crocco, D. Monti, P. Garagnani, C. Franceschi and G. Passarino, Mech Ageing Dev 165(PtB), 147-55 (2017) doi: https://doi.org/10.1016/j.mad.2017.03.011

5. D. You, D. Gu and Z. Yi, J Applied Gerontology 29(3), 308-332 (2010) doi: 10.1177 / 0733464809340154

6. T. Nakagawa, J. Cho, Y. Gondo, P. Martin, M.A. Johnson, L.W. Poon, N. Hirose, Aging Ment Health, 1-8 (2017) doi: https://doi.org/10.1080/13607863.2017.1348477

7. T.N. Berezina, E.I. Mansurov, Voprosy Psikhologii 2015(3), 73-83 (2015) http://www.scopus.com/inward/record.url?eid=2-s2.084941642871\&partnerID=MN8TOARS

8. R. Margolis, J Health Soc Behav 54(3), 353-68 (2013) doi: https://doi.org/10.1177/0022146513489312

9. E. Snippe, B.F. Jeronimus, M. Aan Het Rot, E.H. Bos, P. de Jonge and M. Wichers, The J Pers 86(2), 139-46 (2018) doi: https://doi.org/10.1111/jopy.12299

10. T.N. Berezina, V.I. Ekimova, A.V. Kokurin, E.A. Orlova, Psikhologicheskiy zhurnal 3, 70-78 (2018) DOI: 10.7868/S0205959218030066

11. B.H. Brummett, M.J. Helms, W.G. Dahlstrom, I.C. Siegler, Mayo Clin Proc 81(12), 1541-4 (2006) DOI: https://doi.org/10.4065/81.12.1541

12. P. Novotny, R.C. Colligan, D.W. Szydlo, et al, Journal of Thoracic Oncology 5(3), 326332 (2010) DOI: https://doi.org/10.1097/JTO.0b013e3181ce70e8

13. M. Cho, J Exerc Rehabil. 10(5), 319-325 (2014) https://dx.doi.org/10.12965\%2Fjer.140164

14. E.Y. Cornwell, L.J. Waite, J Health Soc Behav 50(1), 31-48 (2009) DOI: 10.1177 / 002214650905000103

15. R.M. Kaplan, R.G. Kronick, J Epidemiol Community Health 60(9), 760-765 (2006) doi: 10.1136 / jech.2005.037606 PMCID: PMC2566023

16. P.F. McArdle, T.I. Pollin, J. R. O'Connell, et al, J Gerontol A Biol Sci Med Sci 61(2), 190-5 (2006) http://dx.doi.org/10.1093/gerona/61.2.190

17. K.J. Scurrah, J.L. Hopper, Twin research: designs and analytic approaches. Conversations in Twins Research, Twins Research Australia (Melbourne, 2019) https://www.twins.org.au/research/tools-and-resources/125-conversation-in-twinresearch/377-twin-research-designs-and-analytic-approaches

18. S.J. Olshansky, T. Antonucci, L. Berkman, et al, Health Aff (Millwood) 31(8), 1803-13 (2012) doi: http://dx.doi.org/10.1377/hlthaff.2011.0746

19. T.N. Berezina, N.N. Rybtsova, S.A. Rybtsov, G.V. Fatianov, Journal of Modern Foreign Psychology 9(1), 8-21 (2020) DOI: 10.17759/jmfp.20200901011

20. Z. Zimmer, C. Jagger, C.T. Chiu, M.B. Ofstedal, F. Rojo and Y. Saito, SSM Popul Health 2, 373-81 (2016) doi: 10.1016 / j.ssmph.2016.04.009

21. B. Cornwell, E.O. Laumann, L.P. Schumm, Am Sociol Rev 73(2), 185-203 (2008) DOI:10.1177/000312240807300201

22. K. Modig, M. Talback, J. Torssander and A. Ahlbom, J Epidemiol Community Health 71(5), 424-30 (2017) doi: https://doi.org/10.1136/jech-2016-207857 